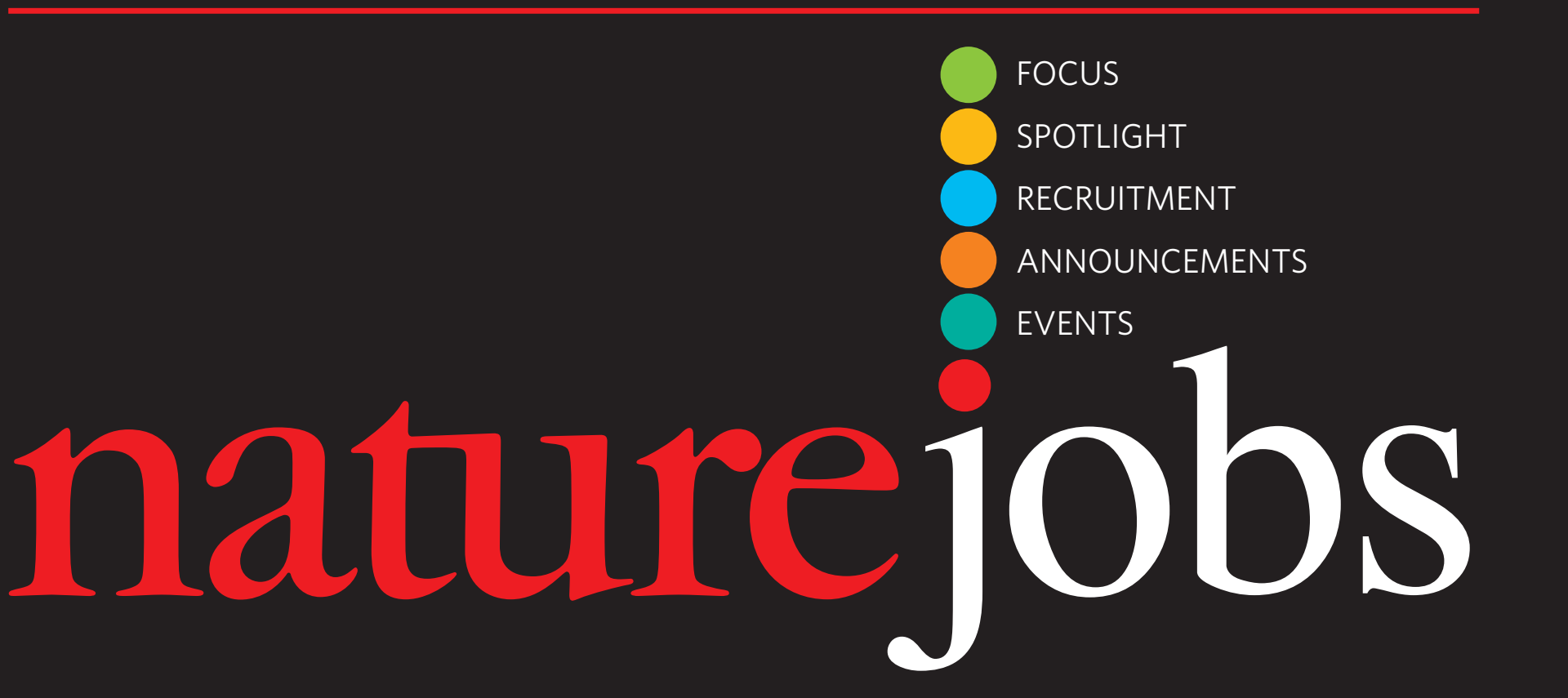

\title{
Reality check
}

Sifting through feedback detailing the work experiences of Naturejobs readers, I was reminded of the chorus to a relatively obscure Lou Reed song that goes: "What's good? Not much at all". Most correspondents were complaining about poor supervision for students and postdocs, noting that the broadly positive sentiments expressed by the writers of our Graduate Journals, and in other articles, failed to resonate with them.

One writer said that there are "many more graduatestudent horror stories for every rare and unusual experience" reported in our Graduate Journals. Another wrote that his experience failed to square with what he called our "rose-coloured" view, adding that "erratic supervision and an experimental design that has only recently revealed its considerable weaknesses have left my fascination with science exhausted". Still another said that many institutions and supervisors are chronically lacking at providing postgrads with guidance, and accuses Naturejobs of saying students should just grin and bear it, and "help each other out to get through it".

The level of vitriol in some of these responses tells me

CONTACTS

Publisher: Ben Crowe

Editor: Paul Smaglik

Marketing Manager: David Bowen

US Head Office, New York

345 Park Avenue South, 10th Floor,

New York, NY 10010-1707

Tel: +1 8009897718

Fax: +18009897103

e-mail: naturejobs@natureny.com

US Sales Manager/Corporations: Peter Bless

Classified Sales Representatives

Tel: +18009897718
New York/Pennsylvania/

Latin America: Kelly Roman

Midwest USA/Maryland/

NIH: Wade Tucker

East USA/Canada:

Janine Taormina

San Francisco Office

Classified Sales Representative:

Michaela Bjorkman

West USA/West Corp. Canada

225 Bush Street, Suite 1453

San Francisco, CA 94104

Tel: +1415 7813803

Fax: +1 4157813805

e-mail:m.bjorkman@naturesf.com that these people are frustrated by the lack of control that they have over their destinies. But although I agree with punk-rock legend John Lydon that "Anger is an energy", I'd add that these disgruntled readers should also listen to the Eric Clapton refrain: "It's in the way that you use it".

On that note, another writer pointed out that rather than complaining or expecting organizations to bail you out, you should be "proactive by taking steps to improve your own situation".

That sentiment has been the goal of Naturejobs from the start. We aim to give solutions and offer advice rather than wallowing in a culture of complaint. In essence, we're heeding the words of English rapper The Streets and focusing on "just trying to stay positive".

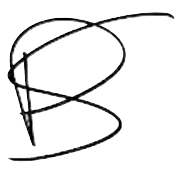

\section{Paul Smaglik, Naturejobs editor}

European Head Office, London

The Macmillan Building,

4 Crinan Street,

London N1 9XW, UK

Tel: +44 (0) 2078434961

Fax: +44 (0) 2078434996

e-mail:naturejobs@nature.com

Naturejobs Sales Director: Nevin Bayoumi (4978) European Sales Manager: Andy Douglas (4975)

Advertising Production Manager: Billie Franklin To send materials use London address above. Tel: +44 (0) 2078434814

Fax: +44 (0) 2078434996

e-mail: naturejobs@nature.com
Naturejobs web development: Tom Hancock Naturejobs online production: Niamh Shields

European Satellite Office

Patrick Phelan

e-mail:p.phelan@nature.com

Japan Head Office, Tokyo

Chiyoda Building,

2-37 Ichigayatamachi,

Shinjuku-ku,

Tokyo $162-0843$

Tel: +81332678751

Fax: +81332678746

Asia-Pacific Sales Director: Rinoko Asami

e-mail: r.asami@naturejpn.com 